\title{
Pengaruh Penambahan Klonidin 75 mcg pada 12,5 mg Levobupivakain 0,5\% Secara Intratekal terhadap Lama Kerja Blokade Sensorik dan Motorik untuk Bedah Ortopedi Ekstremitas Bawah
}

\author{
Fadlyansyah Ramli, ${ }^{1}$ Doddy Tavianto,, ${ }^{2}$ Tinni T. Maskoen ${ }^{2}$ \\ ${ }^{1}$ Instalasi Anestesi dan Rawat Intensif Rumah Sakit Islam Fatimah Cilacap, \\ ${ }^{2}$ Departemen Anestesiologi dan Terapi Intensif \\ Fakultas Kedokteran Universitas Padjadjaran/Rumah Sakit Dr. Hasan Sadikin Bandung
}

\begin{abstract}
Abstrak
Keterbatasan anestesi spinal antara lain ialah lama kerja blokade sensorik dan motorik terbatas. Penelitian ini bertujuan melihat pengaruh penambahan $75 \mathrm{mcg}$ klonidin pada $12,5 \mathrm{mg}$ levobupivakain $0,5 \%$ terhadap lama kerja blokade sensorik dan motorik pada anestesi spinal untuk bedah ortopedi ekstremitas bawah. Penelitian bersifat eksperimental prospektif dengan metode acak terkontrol tersamar ganda pada 36 sampel dengan kriteria American Society of Anesthesiologist (ASA) I-II yang menjalani operasi ortopedi ekstremitas bawah dengan anestesi spinal di Rumah Sakit Dr. Hasan Sadikin Bandung pada bulan Juni-Agustus 2014. Kelompok levobupivakain dan klonidin (LK) mendapatkan 12,5 mg levobupivakain 0,5\% ditambah klonidin 75 mcg. Kelompok levobupivakain dan salin (LS) mendapatkan 12,5 mg levobupivakain 0,5\% ditambah $\mathrm{NaCl}$ 0,9\% 0,5 mL. Data hasil penelitian diuji secara statistik menggunakan uji-t, Mann-Whitney, dan chi-kuadrat. Hasil penelitian menunjukkan lama kerja blokade sensorik kelompok LK lebih lama secara bermakna yaitu $244,44(37,84)$ menit dibandingkan dengan kelompok LS, yaitu 107,89 $(17,63)$ menit $(p=0,000)$. Lama kerja blokade motorik kelompok LK lebih lama secara bermakna yaitu 278,72 $(41,75)$ menit dibandingkan dengan kelompok LS, yaitu 128,39 $(18,26)$ menit $(p=0,000)$. Simpulan, penambahan klonidin 75 mcg pada 12,5 mg levobupivakain $0,5 \%$ secara intratekal memerpanjang lama kerja blokade sensorik dan motorik.
\end{abstract}

Kata kunci: Anestesi spinal, klonidin, levobupivakain, lama kerja blokade sensorik, lama kerja blokade motorik

\section{Effect of Clonidine $75 \mathrm{mcg}$ Addition to Intrathecal $12.5 \mathrm{mg} \mathrm{0.5 \%}$ Levobupivacaine on Sensoric and Motoric Blockade Duration in Lower Extremity Orthopedic Surgery}

\begin{abstract}
Spinal anesthesia has some limitations that limits its use, such as limited duration of action in motoric and sensoric. This research aimed to provide an overview on the effect of adding clonidine $75 \mathrm{mcg}$ to $12.5 \mathrm{mg}$ $0.5 \%$ levobupivacaine on the motoric and sensoric blockade action duration in lower extremity orthopedic surgery spinal anesthesia. This experimental prospective research used double blind randomized controlled trial approach on 36 patients with ASA I-II physical status who underwent lower extremity orthopedic surgery using spinal anesthesia in Dr. Hasan Sadikin General Hospital during the period of June to August 2014. LC group, clonidine $75 \mathrm{mcg}$ was added to $12.5 \mathrm{mg} \mathrm{0.5 \%}$ levobupivacaine. On LS group, $12.5 \mathrm{mg} 0.5 \%$ mg levobupivacaine mixed with $0.5 \mathrm{~mL} 0.9 \% \mathrm{NaCl}$. The data were then statistically tested using t-test, MannWhitney, and chi-square. The result showed that the duration of action of sensoric blockade in LK group was significantly longer, i.e. 224.44 (37.84) minutes compared to LS group, i.e. 107.89 (17.63) minutes $(\mathrm{p}=0.000)$. Duration of action of motoric blockade in LK group was significantly longer, i.e. $278,72(41,75)$ minutes, compared to LS group, i.e. 128.39 (18.26) minutes $(\mathrm{p}=0.000)$. It is concluded that the additiona of clonidine $75 \mathrm{mcg}$ to $12,5 \mathrm{mg}$ 0,5\% levobupivacaine significantly prolongs the duration of action of the motoric and sensoric blockade if given intrathecally.
\end{abstract}

Key words: Clonidine, duration of action, duration of action of motoric blockade, levobupivacaine, spinal anesthesia

Korespondensi: Fadlyansyah Ramli, dr., SpAn, Instalasi Anestesi dan Rawat Intensif Rumah Sakit Islam Fatimah Cilacap, Perumahan Gumulir Indah Blok 14 No. 74, Cilacap, Tlp. 0282-541065, Mobile 081394701364, Email fadlydr@yahoo.com 


\section{Pendahuluan}

Anestesia spinal merupakan salah satu teknik anestesia regional dengan cara memasukkan obat anestesia lokal di dalam ruang intratekal. Banyak keuntungan yang diperoleh dari teknik anestesia regional terutama anestesia spinal, antara lain adalah prosedur pelaksanaan yang lebih singkat, mula kerja cepat, kualitas blokade sensorik dan motorik yang lebih baik, mampu mencegah respons stres lebih sempurna, serta dapat menurunkan perdarahan intraoperatif. Salah satu kelemahan anestesia regional spinal adalah lama kerja yang terbatas, sedangkan kita sering kali dihadapkan pada operasi yang membutuhkan waktu yang lama. ${ }^{1,2}$

Selama ini sering dilakukan penambahan adjuvan pada anestetik lokal yang bertujuan untuk memperpanjang durasi analgesia obat anestesia lokal yang digunakan untuk anestesi spinal. Saat ini terdapat beberapa obat adjuvan yang dapat dipergunakan pada anestesia spinal seperti epinefrin, opioid, agonis reseptor $\alpha_{2}$ adrenergik, antagonis reseptor $N$-methyl- $D$ aspartate (NMDA), agonis reseptor kolinergik, dan penghambat asetilkolinesterase. ${ }^{3}$

Penggunaan opioid serta obat lain sebagai adjuvan sering kali menimbulkan efek samping yang tidak diinginkan terutama depresi napas, mual muntah, serta pruritus. Hal inilah yang memacu peneliti untuk meneliti obat lain yang dapat digunakan sebagai obat adjuvan pada anestesia spinal.

Levobupivakain adalah $S$ (-)- enantiomer murni dari racemic bupivakain tetapi kurang toksik terhadap jantung dan sistem saraf pusat sehingga memiliki marjin lebih besar terhadap potensi keselamatan pasien bila dibandingkan dengan racemic bupivakain. Levobupivakain neuroaksial dapat memberikan analgesia yang cukup efektif pada jenis operasi seksio sesaria, perut bagian bawah, urologi, serta ekstremitas bawah. ${ }^{4,5}$

Klonidin merupakan golongan $\alpha_{2}$ agonis adrenergik yang memiliki kemampuan untuk mempotensiasi efek anestetik lokal. Klonidin dapat meningkatkan blokade sensorik dan juga motorik anestetik lokal. Klonidin intratekal telah digunakan sebagai obat adjuvan anestesi lokal dalam berbagai macam operasi tanpa menimbulkan efek samping yang signifikan.

Mekanisme kerja klonidin intratekal adalah dengan cara melakukan aktivasi postsynaptic $\alpha_{2}$ adrenoseptor di area sumsum tulang belakang. Efek supraspinal klonidin yang berkontribusi sebagai analgesia. Reseptor $\alpha_{2}$ agonis bekerja pada adrenoreseptor di area sumsum tulang belakang serta memblokade konduksi serat $\mathrm{C}$ dan A $\delta$, meningkatkan konduktansi kalium, dan meningkatkan konduksi blokade dari anestesi lokal. Klonidin dapat memperpanjang durasi blokade sensorik dan motorik pada pemberian secara intratekal ke dalam lokal anestesi dan memperkuat potensi antinosiseptif. 6,7

Tujuan penelitian ini adalah mengetahui efek penambahan klonidin 75 mcg terhadap 12,5 mg levobupivakain 0,5\% yang diberikan secara intratekal dalam meningkatkan lama kerja blokade sensorik dan juga motorik pada bedah ortopedi ekstremitas bawah.

\section{Subjek dan Metode}

Penelitian ini dilakukan dengan cara prospektif eksperimental, dengan menggunakan uji klinis acak buta ganda (double blind randomized controlled trial) pada 36 orang pasien dengan American Society of Anesthesiologist (ASA) I-II yang menjalankan pembedahan ortopedi pada ekstremitas bawah dengan anestesia spinal di Rumah Sakit Dr. Hasan Sadikin Bandung pada periode Juni sampai dengan Agustus 2014.

Pengambilan sampel penelitian dilakukan secara consecutive sampling dan alokasi subjek ke dalam salah satu kelompok dilakukan secara random blok permutasi. Hal ini berdasarkan perhitungan statistika menggunakan formula penentuan ukuran sampel untuk penelitian analitis katagorik numerik tidak berpasangan untuk menguji perbedaan rata-rata memakai taraf kepercayaan 95\% serta kuasa uji (power test) 95\%, diperoleh total sampel 36 pasien. Analisis statistika untuk data numerik, nilai $\mathrm{p}$ dihitung berdasarkan uji-t tidak berpasangan apabila data berdistribusi normal, sedangkan data tidak berdistribusi normal menggunakan Uji Mann Whitney.

Perhitungan nilai $\mathrm{p}$ untuk data kategorik 
menggunakan uji chi-kuadrat, alternatif lain adalah menggunakan Uji Kolmogorov Smirvov, nilai statistika dianggap bermakna bila $\mathrm{p}<0,05$. Kriteria inklusi, adalah pasien yang menjalani operasi ortopedi ekstremitas bawah memakai anestesia spinal, status fisik ASA I-II, usia 1860 tahun.

Kriteria eksklusiadalahmempunyairiwayat alergi terhadap obat-obatan yang digunakan pada penelitian, pasien dengan kontraindikasi anestesia spinal, tinggi badan $<155 \mathrm{~cm}$ atau $>175 \mathrm{~cm}$, serta obesitas dengan indeks massa tubuh (IMT) $>30$. Kriteria pengeluaran, yaitu terjadi kegagalan blok spinal setelah ditunggu lebih dari 30 menit serta terjadi penyulit berat selama pembedahan seperti syok serta reaksi anafilaksis.

Setelah peneliti mendapatkan persetujuan dari Komite Etik Penelitian Kesehatan Rumah Sakit Dr. Hasan Sadikin/Fakultas Kedokteran Universitas Padjadjaran Bandung, dilakukan pemilihan subjek penelitian yang memenuhi kriteria inklusi serta tidak termasuk kriteria eksklusi, lalu kepada pasien serta keluarganya dijelaskan tentang prosedur yang akan dialami oleh pasien selama mengikuti penelitian serta menandatangani surat persetujuan (informed consent).

Sampel penelitian dikelompokkan menjadi 2 (dua) kelompok, masing-masing 18 pasien. Kelompok LK diberi 12,5 mg levobupivakain 0,5\% ditambahkan klonidin 75 mcg. Kelompok LS diberikan 12,5 mg levobupivakain 0,5\% ditambah $\mathrm{NaCl}$ 0,9\% 0,5 mL. Pasien dibawa ke dalam kamar operasi dan dipasang alat pantau tensimeter automatis, pulse oksimetri, laju nadi, laju napas, dan elektrokardiografi (EKG). Selanjutnya, pasien dipasang kateter intravena ukuran 18G, diberi cairan Ringer laktat 20 mL/ kgBB 20 menit sebelum tindakan.

Anestesia spinal dilakukan menggunakan jarum spinal berukuran 25G yang ditusukkan ke garis tengah intervertebalis L3-4 dengan bevel jarum menghadap ke arah lateral. Saat didapatkan aliran cairan serebrospinal, bevel jarum diputar ke arah sefalad (dengan patokan memutar pengunci maindrain ke arah kepala), lalu larutan anestesi lokal disuntikkan. Setelah obat anestesi lokal selesai disuntikkan, pasien ditidurkan terlentang memakai satu bantal di kepala. Oksigen diberikan pada pasien dengan binasal kanul $3 \mathrm{~L} /$ menit. Akhir pemberian obat anestesi lokal merupakan dasar perhitungan waktu penelitian.

Tes pinprick dilakukan tiap 1 menit dengan menggunakan jarum 25G sampai didapatkan kriteria Hollmens $\geq 2$ pada daerah dermatom L1 untuk menilai mula kerja blokade sensorik; lalu dilakukan tes pinprick kembali mulai dari L1 ke arah sefalad dengan kriteria Hollmens $\geq 2$ sampai didapatkan blokade sensorik pada dermatom tertinggi. Waktu yang dibutuhkan untuk terjadi regresi sampai dengan kembali ke dermatom L1 dengan kriteria Hollmens $<2$ merupakan penilaian lama kerja blokade sensorik yang dinilai setiap 30 menit.

Mula kerja blokade motorik dinilai dengan skala Bromage setiap 1 menit hingga mencapai skor 3. Setelah itu, penilaian dilanjutkan setiap 30 menit sampai fungsi motorik tungkai pulih kembali (sampai skala bromage $=0$ ).

Tekanan darah, laju nadi, dan juga saturasi oksigen diukur tiap 2,5 menit setelah suntikan selama 30 menit dan setiap 5 (lima) menit selama pembedahan dengan memakai mesin monitor Life Scope 14 Nihon Kohden. Selama operasi, kejadian hipotensi atau penurunan tekanan darah $\geq 20 \%$ dari tekanan darah awal atau sistol $\leq 90 \mathrm{mmHg}$, bradikardia (laju nadi $\leq 50 \mathrm{x} /$ menit) dicatat. Bila terjadi hipotensi, pasien diberikan cairan kristaloid 300-500 mL atau kalau perlu efedrin $5 \mathrm{mg}$ intravena. Bila terjadi bradikardia, diberi sulfas atropin 0,50 mg intravena. Selama operasi berlangsung dicatat jumlah pemakaian efedrin serta sulfas atropin.

\section{Hasil}

Karakteristik umum kedua kelompok menurut usia, tingkat pendidikan, tinggi badan, berat badan, serta ASA tidak didapatkan perbedaan bermakna secara statistika ( $p>0,05$; Tabel 1 ).

Lama kerja rata-rata blokade sensorik untuk kelompok levobupivakain dan klonidin ialah 244,44 menit dengan simpangan baku sebesar 37,84 menit, lama blokade sensorik yang paling cepat adalah 181 menit, sedangkan 
Tabel 1 Karakteristik Pasien Dua Kelompok Penelitian

\begin{tabular}{|c|c|c|c|}
\hline \multirow[b]{2}{*}{ Variabel } & \multicolumn{2}{|c|}{ Kelompok } & \multirow[b]{2}{*}{ Nilai $p$} \\
\hline & $\begin{array}{c}\text { Levobupivakain dan } \\
\text { Klonidin }\end{array}$ & $\begin{array}{c}\text { Levobupivakain dan } \\
\text { Salin }\end{array}$ & \\
\hline $\begin{array}{l}\text { Usia (tahun) } \\
\text { Median } \\
\text { Maksimal } \\
\text { Minimal }\end{array}$ & $\begin{array}{l}31,00 \\
52,00 \\
18,00\end{array}$ & $\begin{array}{l}43,50 \\
58,00 \\
18,00\end{array}$ & 0,144 \\
\hline $\begin{array}{l}\text { Tingkat pendidikan } \\
\text { SD } \\
\text { SMP } \\
\text { SMU } \\
\text { S1 }\end{array}$ & $\begin{array}{c}4 \\
3 \\
11 \\
0\end{array}$ & $\begin{array}{c}1 \\
4 \\
10 \\
3\end{array}$ & 0,145 \\
\hline $\begin{array}{l}\text { Tinggi badan }(\mathrm{cm}) \\
\text { Median } \\
\text { Maksimal } \\
\text { Minimal }\end{array}$ & $\begin{array}{l}164,00 \\
170,00 \\
150,00\end{array}$ & $\begin{array}{l}164,00 \\
175,00 \\
155,00\end{array}$ & 0,924 \\
\hline $\begin{array}{l}\text { Berat badan }(\mathrm{kg}) \\
\text { Mean } \pm \text { SD } \\
\text { Median } \\
\text { Range }\end{array}$ & $\begin{array}{c}59,19(8,06) \\
57,5 \\
27\end{array}$ & $\begin{array}{c}58,31(9,03) \\
57,5 \\
30\end{array}$ & 0,77 \\
\hline $\begin{array}{l}\text { ASA } \\
\text { I (SB) } \\
\text { II (SB) }\end{array}$ & $\begin{array}{c}17(94,4) \\
1(5,6)\end{array}$ & $\begin{array}{c}11(61,1) \\
7(38,9)\end{array}$ & 0,018 \\
\hline
\end{tabular}

lama blokade sensorik yang paling lambat ialah 344 menit. Untuk kelompok levobupivakain dan salin didapatkan rata-rata sebesar 107,89 menit dengan simpangan baku sebesar 17,63 menit, lama blokade sensorik paling cepatialah 90 menit, dan lama blokade sensorik paling lambat adalah 160 menit. Menurut analisis statistika mempergunakan Uji Mann Whitney pada derajat kepercayaan 95\%, menunjukkan bahwa terdapat perbedaan secara bermakna ( $\mathrm{p}<0,05$; Tabel 2; Gambar 1).

Durasi kerja blokade motorik kelompok levobupivakain dengan klonidin didapat ratarata sebesar 278,72 menit dengan simpangan baku sebesar 41,75 menit, lama kerja blokade motorik yang paling cepat 195 menit, dan lama kerja blokade motorik paling lambat ialah 355 menit. Untuk kelompok levobupivakain dengan salin didapat rata-rata sebesar 128,39 menit dengan simpangan baku sebesar 18,26 menit, lama kerja blokade motorik paling cepat 110 menit, dan lama kerja blokade motorik paling lambat adalah 187 menit. Berdasarkan uji statistika menggunakan Uji Mann Whitney didapatkan lama kerja blok kedua kelompok bermakna secara statistika $(\mathrm{p}<0,05$; Tabel 3; Gambar 2).

Insidens hipotensi yang diberikan efedrin pada kelompok perlakuan levobupivakain yang ditambah klonidin lebih banyak dibandingkan

Tabel 2 Perbandingan Lama Kerja Blokade Sensorik

\begin{tabular}{lccc}
\hline \multirow{2}{*}{$\begin{array}{c}\text { Lama Kerja Blokade Sensorik } \\
\text { (menit) }\end{array}$} & \multicolumn{2}{c}{ Kelompok } & Nilai p \\
\cline { 2 - 3 } & $\begin{array}{c}\text { Levobupivakain dan } \\
\text { Klonidin }\end{array}$ & $\begin{array}{c}\text { Levobupivakain } \\
\text { dan Salin }\end{array}$ & \\
\hline Rata-rata (SB) & $244,44(37,84)$ & $107,89(17,63)$ & 0,000 \\
Median & 244 & 101 & \\
Maksimum & 344 & 160 & \\
Minimum & 181 & 90 & \\
\hline
\end{tabular}




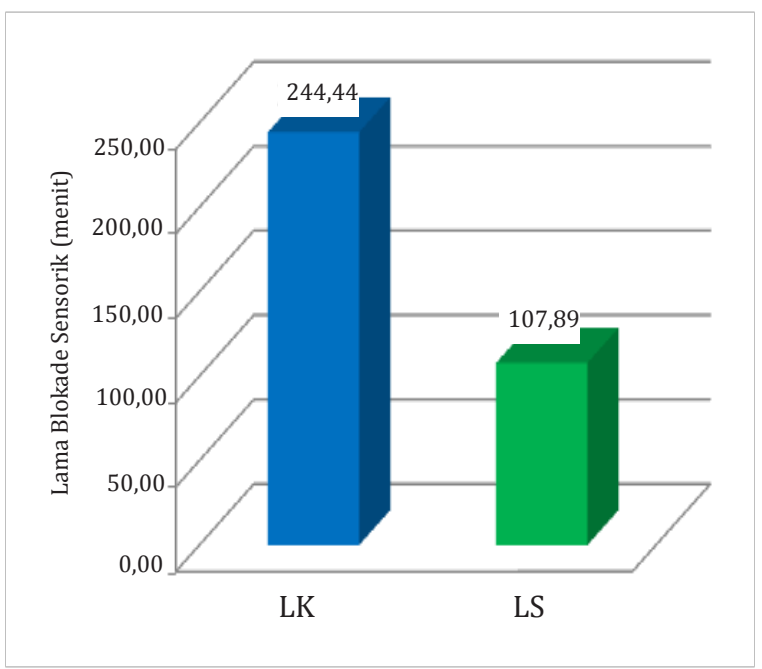

\section{Gambar 1 Grafik Perbandingan Lama Kerja Blokade Sensorik antara Kelompok Klonidin dan Salin}

dengan kelompok levobupivakain ditambah salin. Kejadian efek samping lain tidak terjadi pada kedua kelompok. Pengujian efek samping secara statistika tidak dapat dilakukan karena jumlah sampel tidak mencukupi.

\section{Pembahasan}

Levobupivakain adalah suatu S(-)-enantiomer murni dari racemic bupivakain, yang telah dikembangkan sebagai jenis anestetika lokal pilihan selain dari bupivakain. Levobupivakain memilikiafinitas lebih rendah dengan kekuatan yang berefek menekan fungsi miokardium dan sistem saraf pusat pada studi farmakodinamik dan juga farmakokinetik. Levobupivakain yang dipergunakan untuk spinal secara umum dapat digunakan dengan baik pada prosedur seksio sesaria, perut bagian bawah, transurethral endoscopic, dan ekstremitas bawah.,

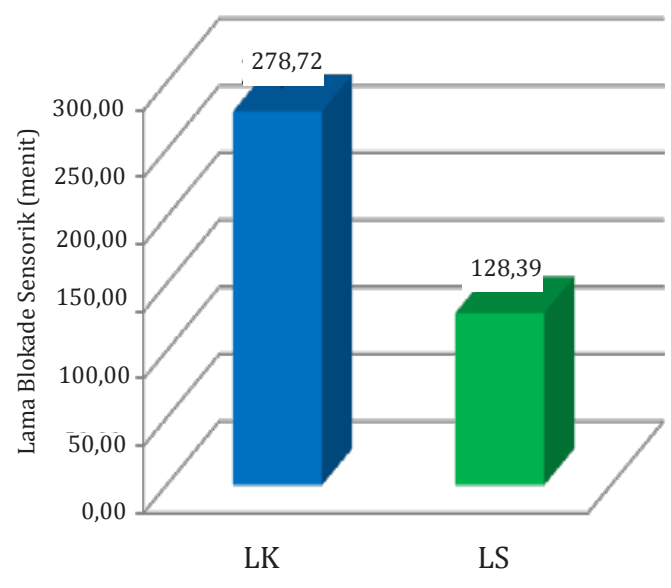

\section{Gambar 2 Grafik Lama Kerja Blokade Motorik Kelompok Klonidin dan Salin}

Terdapat beberapa metode yang dilakukan untuk dapat meningkatkan lama kerja blokade sensorik dan juga motorik obat anestesia lokal yang dipergunakan pada anestesia spinal, baik dengan cara meningkatkan dosis anestetik lokal maupun penambahan obat adjuvan ke dalam anestetik lokal tersebut. Telah banyak dilakukan penelitian mengenai penambahan adjuvan ke dalam obat anestesia lokal guna meningkatkan durasi kerja blokade anestesia lokal dengan melihat efek samping yang harus minimal dan tidak berdampak baru bagi pasien. Pada penelitian ini dipergunakan penambahan adjuvan klonidin ke dalam obat anestesia lokal levobupivakain guna meningkatkan lama kerja blokade sensorik dan motorik levobupivakain yang digunakan untuk anestesi spinal.

Dalam penelitian ini, peneliti menggunakan klonidin (golongan $\alpha_{2}$ adrenoseptor agonist) sebagai obat tambahan levobupivakain pada

Tabel 3 Perbandingan Lama Kerja Blokade Motorik

\begin{tabular}{lccc}
\hline \multirow{2}{*}{$\begin{array}{c}\text { Lama Kerja Blok } \\
\text { (menit) }\end{array}$} & \multicolumn{2}{c}{ Kelompok Sampel } & \multirow{2}{*}{ Nilai p } \\
\cline { 2 - 3 } & LK & LS & \\
\hline Rata-rata (SB) & $278,72(41,75)$ & $128,39(18,26)$ & \\
Median & 282,5 & 127,5 & 0,000 \\
Maksimum & 355 & 187 & \\
Minimum & 195 & 110 & \\
\hline
\end{tabular}


anestesia spinal. Mekanisme kerja klonidin dalam mempotensiasi blokade sensorik pada anestesi spinal dimediasi oleh efek presynaptic (menghambat pelepasan transmitter) dan juga postsynaptic (meningkatkan hiperpolarisasi). Klonidin dapat mempotensiasi efek anestesia lokal dan menurunkan dosis yang dibutuhkan. Analgesia yang terjadi disebabkan karena efek tambahan ataupun efek sinergis sekunder dari berbagai macam mekanisme kerja anestesia lokal serta $\alpha_{2}$ adrenoseptor agonist. Anestesia lokal menghambat saluran natrium, sebaliknya $\alpha_{2}$ adrenoseptor agonist bekerja dengan cara mengikat serabut-serabut saraf tipe $C$ dan juga saraf-saraf post synaptic di dorsal horn medula spinalis. Intratekal $\alpha_{2}$ adrenoseptor agonist menghasilkan analgesia dengan cara menekan pelepasan transmitter dari serabut saraf tipe $C$ dan dengan cara hiperpolarisasi saraf-saraf post synaptic di dorsal horn medula spinalis. Mekanisme kerja klonidin didapatkan dari efek antinosiseptif medula spinalis melalui post junctional $\alpha_{2}$ adrenoreseptor yang dimediasi melalui pelepasan noreadrenaline pada dorsal horn. Efek antinosiseptif tersebut yang dapat menjelaskan terjadinya perpanjangan blokade sensorik ketika ditambahkan untuk anestesia spinal. Efek analgesia klonidin akan dimediasi secara spinal ke dalam aktivasi dari reseptor $\alpha_{2}$ post synaptic dalam substansia gelatinosa dari medula spinalis. ${ }^{8-10}$

Alfa- ${ }_{2}$ adrenoseptor agonist mempotensiasi intensitas serta durasi kerja blokade motorik dengan cara menekan modifikasi selular dalam ventral horn medula spinalis (hiperpolarisasi motorneuron) serta memfasilitasi kerja obat anestesia lokal. Perpanjangan blokade motorik pada anestesia spinal terjadi sebagai akibat pengikatan $\alpha_{2}$ adrenoseptor agonist pada saraf motorik di medula spinalis. ${ }^{8,9}$

Angka kejadian hipotensi dan penggunaan efedrin lebih banyak terjadi pada kelompok levobupivakain dengan klonidin dibandingkan dengan levobupivakain dengan salin. Hasil ini menunjukkan bahwa klonidin meningkatkan potensi anestetik lokal sehingga blokade saraf autonom simpatik di torakolumbal menjadi semakin kuat. Penurunan tekanan darah ini dapat diakibatkan oleh kerja klonidin di dalam batang otak, yang pada pemberian klonidin secara intratekal dapat dicapai dengan cara redistribusi sistemik atau melalui penyebaran ke arah kepala melalui cairan serebrospinal. ${ }^{11}$ Pengujian statistika kejadian efek samping tidak dapat dilakukan karena jumlah sampel yang tidak memenuhi syarat.

\section{Simpulan}

Berdasarkan pengujian hasil penelitian serta pembahasan, maka dapat disimpulkan bahwa penambahan $75 \mathrm{mcg}$ klonidin dalam 12,5 mg levobupivakain $0,5 \%$ memperpanjang lama kerja blokade sensorik serta motorik anestesia intratekal.

\section{Daftar Pustaka}

1. Kleinman W, Mikhail M. Spinal, epidural, \& caudal blocks. Dalam: Morgan GE, Murray MJ, penyunting. Clinical anesthesiology. Edisi ke-6. New York: McGraw-Hill; 2006. hlm. 289-323.

2. Bernards CM. Epidural and spinal anesthesia. Dalam: Barash P, Cullen $\mathrm{BF}$, Stoelting $\mathrm{R}$, penyunting. Clinical anesthesia. Edisi ke-6. Philadelphia: Lippincott Williams \& Wilkins; 2009. hlm. 928-54.

3. Vadalouca A. Adjuvant drugs. Dalam: Miller $\mathrm{R}$, penyunting. Miller's anesthesia. Edisi ke-7. New York: Churchill Livingstone; 2009. hlm. 244-61.

4. Burlacu CL, Dona JB. Update on local anesthetics: focus on levobupivacaine. Theurapeutics Clin Risk Manage. 2008;4:381-92.

5. Sanford M, Gillian M. Levobupivacain a review of its use in regional anesthesia and pain management. Adis Drugs Evaluation. 2010;70:761-91.

6. Thakur A, Mamta B, Kaur K, Dureja J, Hooda S, Taxak S. Intratechal clonidine as an adjuvant to hyperbaric bupivacaine in patients undergoing inguinal herniorraphy: a randomized doubleblinded study. J Anaesth Clin Pharm. 
2013;29:66-70.

7. Shah Z, Kundal R, Gupta A, Malla M, Zahoor F, Kundal V, dkk. Efficacy of analgesic effect of low dose intrathecal clonidine as adjuvant to bupivacaine in urogenital surgeries: study in a kashmiri population. Indian J Anaesth. 2007;51:418-23.

8. Bhure A, Kalita N, Ingley P. Comparative study of intrathecal hyperbaric bupivacaine with clonidine, fentanyl, and midazolam for quality of anaesthesia and duration of post operative pain relief in patients undergoing elective caesarean section. People's J Scientific Research. 2012;5(1):19-23.

9. Kanazi G, Aouad M, Jabbour S, Jazzar A,
Yaman A, Bulbul M, dkk. Effect of lowdose dexmedetomidine or clonidine on the characteristics of bupivacaine spinal block. Acta Anaesthesiol Scand. 2006;50:222-7.

10. Sanghvi K, Shah V, Patel D. Comparative study of bupivacaine alone and bupivacaine along with buprenorphine in axillary brachial plexus block: a prospective, randomized, single blind study. Intern J Basic Clin Pharmacol. 2013;2:640-4.

11. Agarwal D, Chopra M, Mohta M. Clonidine as an adjuvant to hyperbaric bupivacaine for spinal anesthesia in elderly patients undergoing lower limb orthopedic surgeries. Saudi J Anesth. 2014;8:209-14. 